\title{
Bilateral Anterior Shoulder Fracture-Dislocation: About a Case
}

\author{
Songahir Christophe Da ${ }^{1}$, Sayouba Tinto ${ }^{1}$, Alexandre Stanislas Korsaga ${ }^{1}$, \\ Anatole Jean Innocent Ouedraogo ${ }^{2}$, Zoewemdtalé Fabrice Ouedraogo ${ }^{1}$, Christian Darga', \\ Mamoudou Sawadogo ${ }^{1 *}$, Hamado Kafando', Mohamed Tall ${ }^{1}$
}

\author{
${ }^{1}$ Yalgado Ouedraogo University Hospital, Ouagadougou, Burkina Faso \\ ${ }^{2}$ Blaise Compaore University Hospital, Ouagadougou, Burkina Faso \\ Email: *smamoudou@hotmail.com
}

How to cite this paper: Da, S.C., Tinto, S., Korsaga, A.S., Ouedraogo, A.J.I., Ouedraogo, Z.F., Darga, C., Sawadogo, M., Kafando, H. and Tall, M. (2018) Bilateral Anterior Shoulder Fracture-Dislocation: About a Case. Open Journal of Orthopedics, 8, 183-189.

https://doi.org/10.4236/ojo.2018.85021

Received: March 6, 2018

Accepted: May 20, 2018

Published: May 23, 2018

Copyright $\odot 2018$ by authors and Scientific Research Publishing Inc. This work is licensed under the Creative Commons Attribution International License (CC BY 4.0).

http://creativecommons.org/licenses/by/4.0/

\begin{abstract}
Bilateral anterior dislocations of the shoulder are rare lesions. They are even rarer when combined with a bilateral fracture of major tubercles. We report the case of a 28-year-old patient admitted to trauma emergencies after trauma by falling from the top of a stool. Clinical and radiographic findings revealed bilateral anterior shoulder dislocation associated with bilateral fracture of major tubercles. The patient was treated orthopedically by a reduction of dislocations under General Anesthesia, immobilization of the shoulders for 6 weeks followed by reeducation. The functional result after 12 months was satisfactory with a UCLA score of 30 points.
\end{abstract}

\section{Keywords}

Bilateral Fracture-Dislocation, Shoulder, Mechanism, Treatment

\section{Introduction}

Dislocation of the shoulder is defined by a total and permanent loss of contact between the humeral head and the glenoid cavity. When this dislocation is associated with a fracture of the proximal end of the humerus, it is fracture dislocation of the shoulder [1]. Although anterior dislocations of the glenohumeral joint are the most frequent dislocations, bilateral forms are very rare [2]. These anterior dislocations are even rarer when combined with a fracture of the major tubercle. Thirty cases of bilateral anterior dislocation have been reported [2], including 15 cases of bilateral dislocation fracture [3]. The aim of this study is to report a case of bilateral fracture-dislocation of the shoulder in a young manual worker, to discuss its mechanism and treatment. 


\section{Observation}

A 28-year-old right-handed apprentice mason was admitted in emergency for pain and total functional impotence of both shoulders in the wake of a closed trauma, which had occurred for 2 hours. The patient, in a cafeteria, experienced vertigo, causing him to fall from the stool on which he was sitting, from a height of approximately 1.20 meters. He received first on his hands and then on the buttocks. The patient had no history of shoulder trauma or unstable shoulder. The physical examination found signs of anterior dislocation of both shoulders (Figure 1). The vasculo-nervous examination was normal. Standard X-ray of both shoulders showed symmetrical bilateral antero-medial dislocation with a sub-coracoid position of the humeral head associated with fracture of the two major tubercles (Figure 2).

Fractures dislocations were treated under general anesthesia by reduction by external maneuver according to Kocher's method. Control x-ray images showed a satisfactory reduction in dislocations and fractures of major tubercles. Bilateral Mayo Clinic immobilization using a tubular jersey $10 \mathrm{~cm}$ in diameter was performed for three weeks (Figure 3). Clinical control at 3 weeks was normal, but immobilization by the mayo clinic was poor due to distension of the jersey, and uncomfortable for the patient. We replaced it by a bilateral scarf. Ten active-passive functional rehabilitation sessions of the shoulder were performed in the patient, at a rate of 2 re-education sessions per week for 5 weeks.

$\mathrm{X}$-rays of control of the shoulders at six months of follow-up objectified a consolidation of the fractures of the major tubercles (Figure 4). Functionally, at the level of both shoulders, the antepulsion was $160^{\circ}$, the abduction $150^{\circ}$, the lateral and medial rotations respectively $70^{\circ}$ and $80^{\circ}$ (Figure 5). Based on the University of California in Los Angeles (UCLA) rating scale [4], the patient scored 32 points. The clinical examination did not find signs of hyperlaxity. The patient was allowed to return to work. At the 12-month follow-up, the patient did not report the presence of instability or recurrence of dislocation.

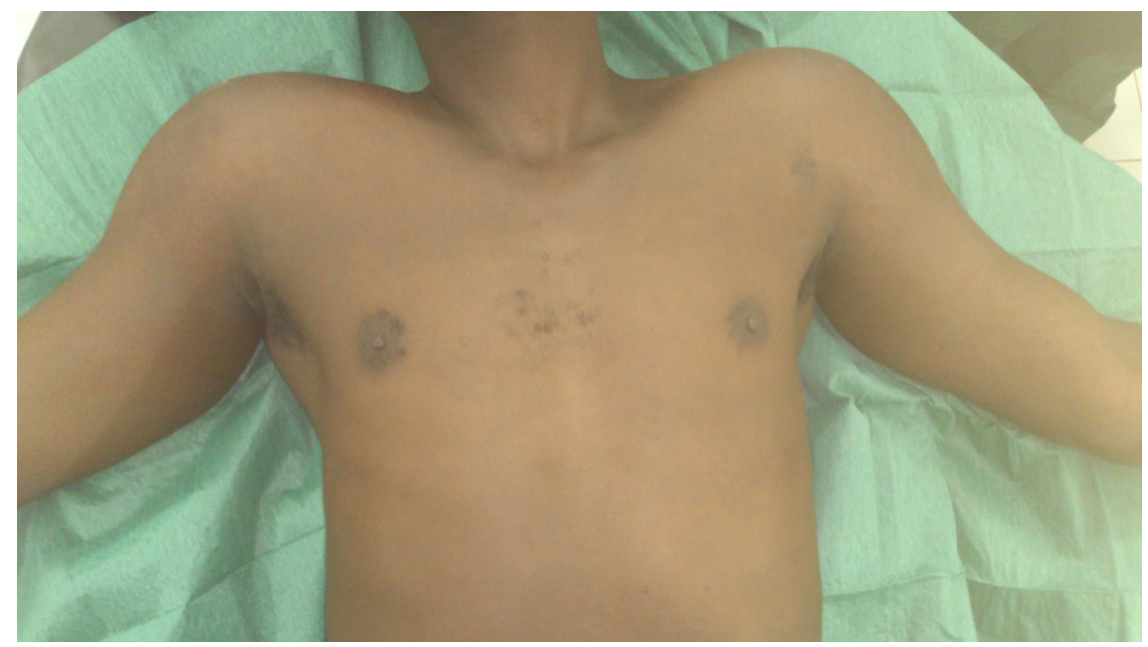

Figure 1. Vicious attitude of shoulders in abduction. 

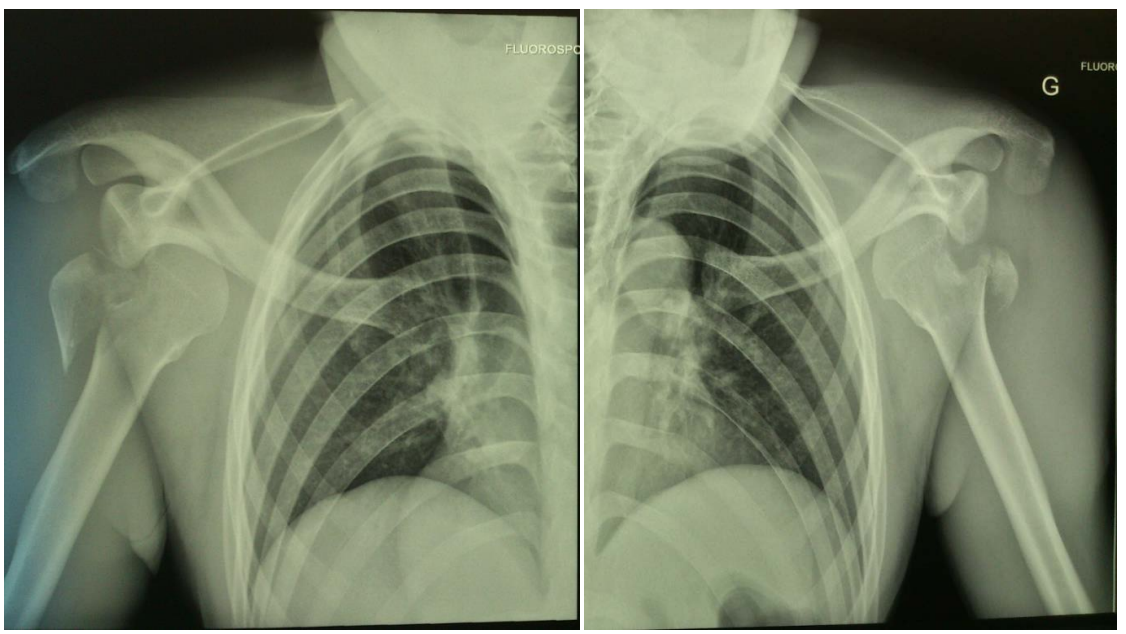

Figure 2. X-ray of the shoulders showing the antero-medial glenohumeral dislocations associated with trochiter fractures.

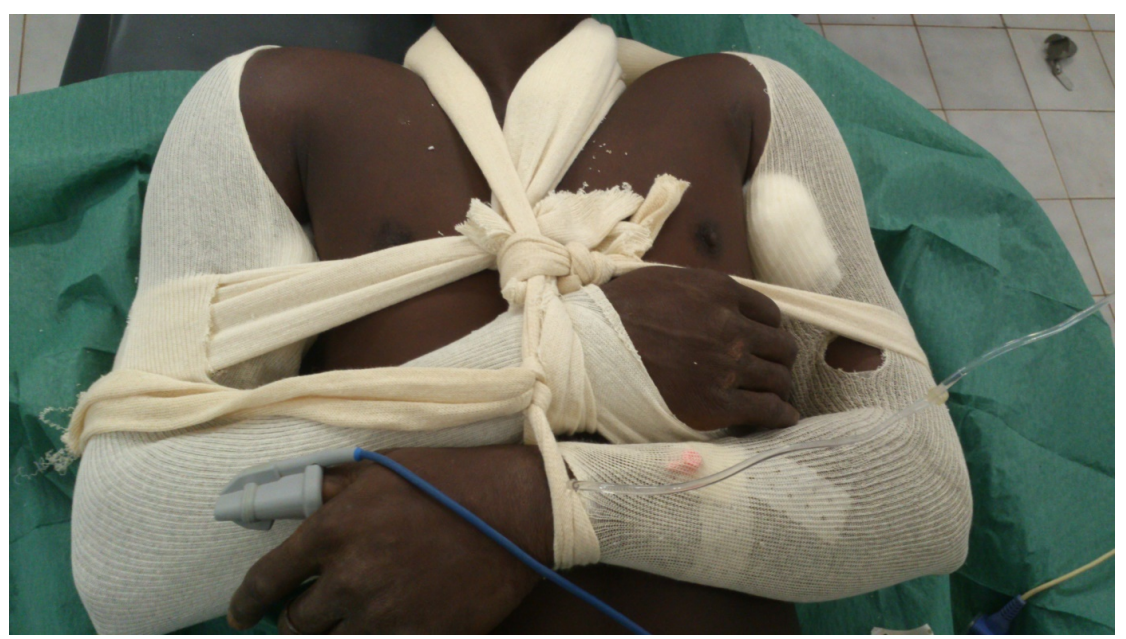

Figure 3. Immobilization of the patient with mayo clinic bilateral.

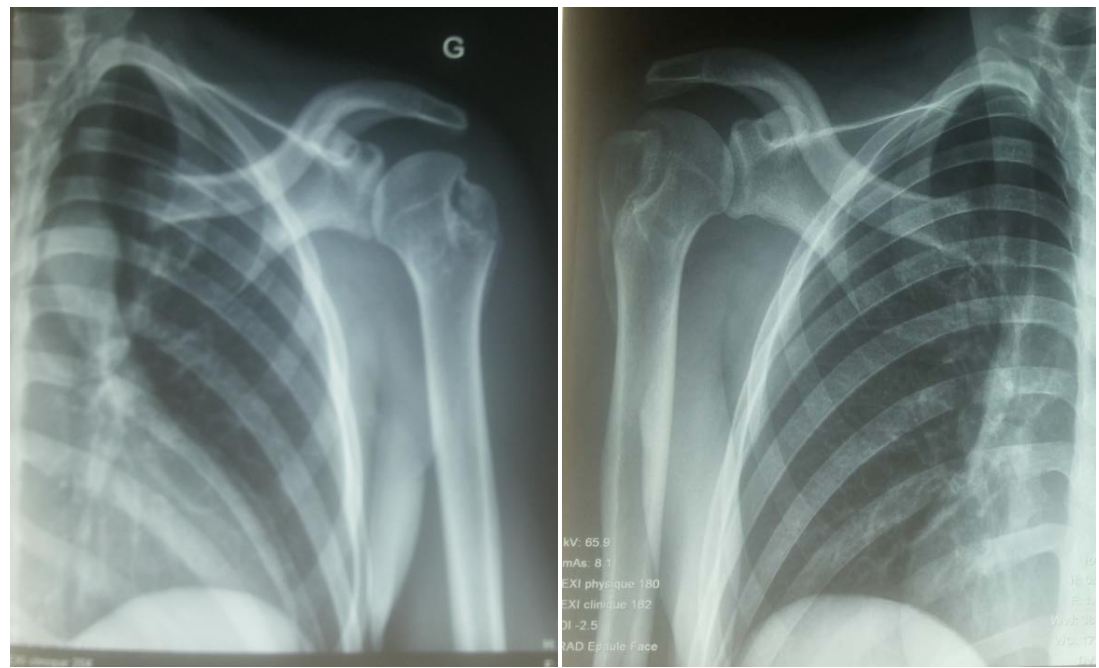

Figure 4. X-ray of shoulder control in the sixth month, showing reduced scapulo humeral joints and consolidation of trochiters. 


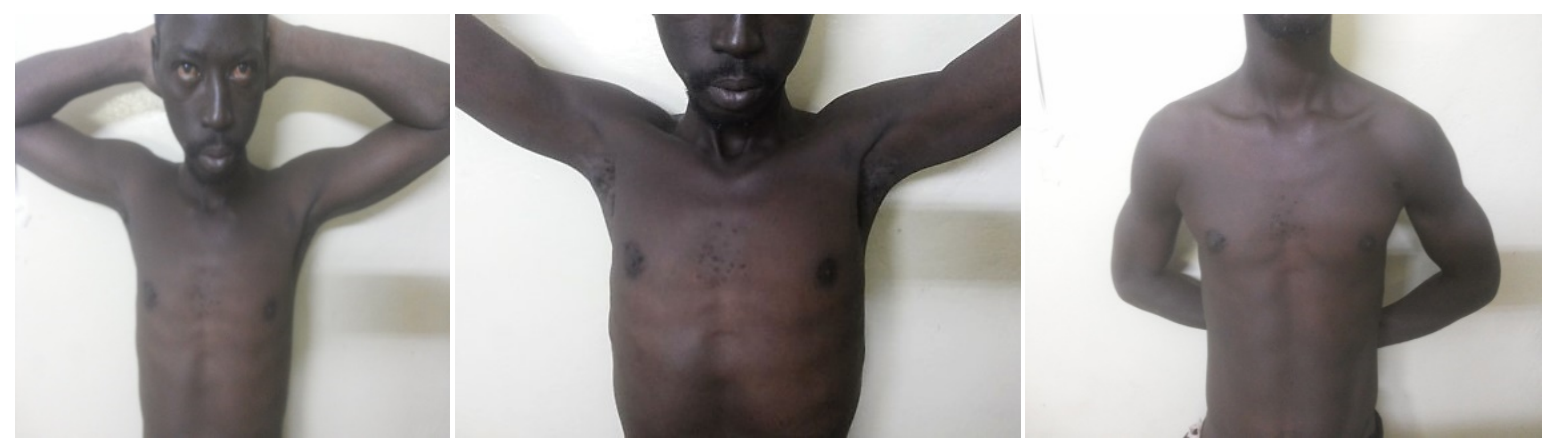

Figure 5. Functional result after six months of dislocation.

\section{Discussion}

Brown [5] in 1984 individualized, on a series of 90 cases of bilateral dislocations, three different etiologies: violent muscular contractions (49\%), direct trauma (23\%) and the absence of any trauma (36\%). These dislocations may be posterior, and this is the most frequent variety according to Bouras et al. [6], Ryan J. and Whitten M. [7].

Anterior varieties are rare and among them, about fifteen cases of bilateral dislocation fractures have been reported [2] [3]. They were secondary to violent trauma, sports accidents, electrocution, epileptic seizures or nocturnal hypoglycemia in diabetics [8] [9] [10] [11]. The particularity of the case that we report is that the bilateral anterior dislocation-fracture occurred after a mild trauma, not in an elderly person as reported by Dlimi et al. [3] but rather in a young and active subject. Our patient suffered a fall from the top of a stool about 1.20 meters. During the fall, the patient had the reflex to use both hands to cushion the shock against the ground thus receiving a reception on both hands, the elbows in extension, the shoulders in abduction and retropulsion. The fall thus accentuated the abduction and lateral rotation of the two shoulders, at the origin of bilateral anterior dislocation. Given the low height of the fall and the young age of our manual worker patient, this mechanism was supplemented by a violent reflex contraction of the rotator cuff muscles during the impact against the ground, explaining the symmetrical and bilateral avulsion of major tubercles. Ryan $\mathrm{J}$ et al. [7] reported an association of a major tubercle fracture in 15\% of cases of anterior dislocation. Abalo et al. [12] reported a case of bilateral anterior dislocation associated with a partial fracture of the major humerus tubercle on the right, in a 37-year-old patient. In the report by these authors, although the patient is young as in ours, it was a violent trauma following a road accident. In the case reported by Abalo et al. [12], the fracture of the major tubercle was unilateral on the right while our patient had a bilateral and symmetrical fracture of the major tubercles. Which means that in our patient, the constraints that led to this lesionalassociation, were exercised on both shoulders with the same force symmetrically and synchronously. Benign trauma as a cause of anterior fracture-dislocation has also been reported by Dlimi et al. [3] with the difference that in the case that these authors reported, it was a woman aged 76 cases who 
fell from a staircase with reception on the upper limbs stretched in abduction and rotation external. Other circumstances of occurrence of bilateral anterior shoulder fractures-dislocations have been described in young patients. Thus Tejas et al. [13] and Ashish et al. [14] each reported a case of bilateral anterior dislocation associated with bilateral major tubercle fracture following tonicoclonicepileptic seizure, respectively, in subjects aged 35 and 45 years. Most authors agree on the orthopedic treatment of shoulder dislocations including bilateral dislocations. Surgery is only considered in case of recurrence. Recurrence is more common in patients younger than 40 years [8] [12]. Thirty cases of bilateral dislocations reported in the literature have been treated orthopedically [2]. Of the fifteen cases of bilateral anterior dislocation fracture reported, the therapeutic attitude was not was not the same for everyone. Orthopedic reduction of dislocation was performed as first-line. Surgical treatment was reserved for failure of orthopedic reduction or failure to reduce avulsion of the major tubercle after reduction of dislocation [3] [13] [14]. The bilateral nature of the fracture-dislocated shoulder had no influence on our therapeutic approach. The patient was treated $1 \mathrm{~h} 30 \mathrm{~min}$ after admission, i.e. $3 \mathrm{~h} 30 \mathrm{~min}$ after the trauma, by a reduction of dislocations under general anesthesia according to the Kocher technique. Like unilateral anterior shoulder dislocation, the techniques used to reduce bilateral dislocation vary among the authors. Abalo et al. [12] used the Kocher technique. Kaldadak et al. [15] reporting two cases of bilateral anterior dislocations used the Milch technique. We used the method of which we master the technique that we practice often. After radiographic examination of the good reduction of the dislocation and especially of the fracture of the major tubercles, we did not indicate any surgical gesture of fixation of the major tubercles. Tejas et al. [13] reporting a case of neglected bilateral anterior dislocation of the shoulder, performed orthopedic treatment on the left side. On the right side, after an unsuccessful attempt to orthopedic reduction, they opted for a surgical reduction with a repositioning of the major tubercle fixed by trans-bone points. The bilateral Mayo Clinic as a method of immobilizing the shoulders, in addition to being damaged after 10 days, was uncomfortable for the patient. It was renewed once during the six weeks of immobilization. The short treatment time in our patient facilitated the reduction in the operating room. Functional deficiency is often observed if the major tubercle is not anatomically reduced [16]. In our patient, radiographic control after treatment, showed a good reduction, hence the good UCLA score of 32 out of 35 points at the 6-month follow-up. The three missing points were the persistence of mild pain and the arm lift that was slightly decreased.

\section{Conclusion}

Bilateral anterior shoulder dislocation associated with bilateral fracture of major tubercles remains a rare associated lesion, caused by an unusual causal mechanism. The exceptional nature of the lesion did not affect our therapeutic attitude. 
Orthopedic treatment has resulted in satisfactory anatomical and functional results.

\section{References}

[1] Gerber, C. and Nyffeler, R.W. (2002) Classification of Glenohumeral Joint Instability. Clinical Orthopaedics \& Related Research, 400, 65-76.

[2] Dunlop, C.C. (2002) Bilateral Anterior Shoulder Dislocation. A Case Report and Review of the Literature. Acta Orthopaedica Belgica, 68, 168-170.

[3] Dlimi, F., Mahfoud, M., Lahlou, A., El Bardouni, A., Berrada, M.S. and El Yaacoubi, M. (2012) Bilateral Anterior Shoulder Dislocation with Bilateral Fractures of the Greater Tuberosity: A Case Report. Journal of Clinical Orthopaedics and Trauma, 3, 122-125. https://doi.org/10.1016/j.jcot.2011.04.001

[4] Harvie, P., Chennagiri, R.J., Pollard, T.C.B. and Carr, A.J. (2005) The Use of Outcome Scores in Surgery of the Shoulder. The Journal of Bone and Joint Surgery. British Volume, 87-B, 151-154. https://doi.org/10.1302/0301-620X.87B2.15305

[5] Brown, R.J. (1984) Bilateral Dislocation of the Shoulders. Injury, 15, 267-273. https://doi.org/10.1016/0020-1383(84)90012-3

[6] Bouras, Y., Elandaloussi, Y., Nadil, M.A., Essarouali, A., Bennouna, D., Fadili, M., et al. (2009) Bilateral Anterior Dislocation of the Shoulders in the Bodybuilder (about a Case). Journal of Sports Traumatology, 26, 247-249. https://doi.org/10.1016/j.jts.2009.10.002

[7] Ryan, J. and Whitten, M. (1997) Bilateral Locked Posterior Shoulder Dislocation in a Footballer. British Journal of Sports Medicine, 31, 74-75. https://doi.org/10.1136/bjsm.31.1.74

[8] Devalia, K.L. and Peter, V.K. (2005) Bilateral Post-Traumatic Anterior Shoulder Dislocation. Journal of Postgraduate Medicine, 51, 72-73.

[9] Galois, L., Traversari, R., Girard, D., Mainard, D. and Delagoutte, J. (2003) Asymmetrical Bilateral Shoulder Dislocation. SICOT Online Rep. February 2003:E024.

[10] Iosifidis, M., Giantsis, G., Giannoulis, J., Malioufas, L., Traios, S. and Tomtsis, C. (2004) Simultaneous Bilateral Posterior Dislocation of the Shoulder: Case Report. $J$ Hell Assoc Orthop Traumatol, 55.

[11] Sreesobh, K. and Chako, B. (2005) An Unusual Case of Bilateral Anterior Dislocation of Shoulder. Journal of Orthopaedics, 2, e6.

[12] Abalo, A., Dossim, A., Songné, B. and Ayouba, G. (2008) Bilateral Anterior Dislocation of the Shoulders. A Case Report. Chirurgie de la Main, 27, 118-121. https://doi.org/10.1016/j.main.2008.04.005

[13] Tejas, U., Abhinav, B. and Sonu, M. (2016) Bilateral Neglected Anterior Shoulder Dislocation with Greater Tuberosity Fractures. Journal of Orthopaedic Case Reports, 6, 53-56.

[14] Ashish, S., Amber, M., Snehal, D. and Neeti, K. (2012) Bilateral Anterior Shoulder Dislocation with Symmetrical Greater Tuberosity Fracture Following Seizure. Journal of Orthopaedic Case Reports, 2, 28-31.

[15] Kaldadak, K., Bouchaib, C., Salim, B. and Belkacem, C. (2015) Distinctive Anterior Bilateral Dislocations of the Shoulders with a Particular Mechanism: About Two Cases. The Pan African Medical Journal, 22, 178. https://doi.org/10.11604/pamj.2015.22.178.7435 
[16] Neer, C.S. (1970) Displaced Proximal Humeral Fractures. The Journal of Bone and Joint Surgery. American Volume, 52, 1077-1089.

https://doi.org/10.2106/00004623-197052060-00001 